University of Nebraska - Lincoln

DigitalCommons@University of Nebraska - Lincoln

May 2000

\title{
The surface terminal layer and composition of the colossal magnetoresistance perovskite: $\mathrm{La}_{0.65} \mathrm{~Pb}_{0.35} \mathrm{MnO}_{3}$
}

\author{
C.N. Borca \\ University of Nebraska-Lincoln \\ Delia Ristoiu \\ CNRS Laboratoire Louis Nee'l, 25 avenue des Martyrs BP 166, 38042 Grenoble CEDEX 09, France \\ Q.L. Xu \\ University of Nebraska-Lincoln \\ Sy_Hwang Liou \\ University of Nebraska-Lincoln, sliou@unl.edu \\ Shireen Adenwalla \\ University of Nebraska-Lincoln, sadenwalla1@unl.edu \\ See next page for additional authors
}

Follow this and additional works at: https://digitalcommons.unl.edu/physicsdowben

Part of the Physics Commons

Borca, C.N.; Ristoiu, Delia ; Xu, Q.L.; Liou, Sy_Hwang; Adenwalla, Shireen; and Dowben, Peter A., "The surface terminal layer and composition of the colossal magnetoresistance perovskite: $\mathrm{La}_{0.65} \mathrm{~Pb}_{0.35 \mathrm{MnO}_{3} "}$ (2000). Peter Dowben Publications. 78.

https://digitalcommons.unl.edu/physicsdowben/78

This Article is brought to you for free and open access by the Research Papers in Physics and Astronomy at DigitalCommons@University of Nebraska - Lincoln. It has been accepted for inclusion in Peter Dowben Publications by an authorized administrator of DigitalCommons@University of Nebraska - Lincoln. 


\section{Authors}

C.N. Borca, Delia Ristoiu, Q.L. Xu, Sy_Hwang Liou, Shireen Adenwalla, and Peter A. Dowben 


\title{
The surface terminal layer and composition of the colossal magnetoresistance perovskite: $\mathrm{La}_{0.65} \mathrm{~Pb}_{0.35} \mathrm{MnO}_{3}$
}

\author{
C. N. Borca \\ Department of Physics and Astronomy and the Center for Materials Research and Analysis, \\ Behlen Laboratory of Physics, University of Nebraska-Lincoln, Lincoln, Nebraska 68588-0111 \\ Delia Ristoiu \\ CNRS Laboratoire Louis Neél, 25 avenue des Martyrs BP 166, 38042 Grenoble CEDEX 09, France
}

\begin{abstract}
Q. L. Xu, S.-H. Liou, S. Adenwalla, and P. A. Dowben ${ }^{\text {a) }}$
Department of Physics and Astronomy and the Center for Materials Research and Analysis, Behlen Laboratory of Physics, University of Nebraska-Lincoln, Lincoln, Nebraska 68588-0111
\end{abstract}

\begin{abstract}
The composition in the surface region of the colossal magnetoresistance perovskite manganite materials, $\mathrm{La}_{0.65} \mathrm{~Pb}_{0.35} \mathrm{MnO}_{3}$ has been studied using angle resolved $\mathrm{X}$-ray photoemission spectroscopy. The results are consistent with a $\mathrm{Mn}-\mathrm{O}$ terminal layer and $\mathrm{Pb}$ segregation to the near-surface region. This is similar to the behavior exhibited by $\mathrm{La}_{0.65} \mathrm{Ca}_{0.35} \mathrm{MnO}_{3}$ and $\mathrm{La}_{0.65} \mathrm{Sr}_{0.35} \mathrm{MnO}_{3}$. The $\mathrm{O}-\mathrm{Mn}-\mathrm{O}$ terminal layer appears to be close to the $\mathrm{Mn}^{3+}$ valence state. (C) 2000 American Institute of Physics. [S0021-8979(00)51108-6]
\end{abstract}

\section{INTRODUCTION}

The colossal magnetoresistance (CMR) perovskite transition metal oxides, $\mathrm{La}_{0.65} \mathrm{~A}_{0.35} \mathrm{MnO}_{3}(\mathrm{~A}=\mathrm{Ca}, \mathrm{Sr}, \mathrm{Ba})^{1,2}$ have been studied extensively, but the related $\mathrm{La}_{1-x} \mathrm{~Pb}_{x} \mathrm{MnO}_{3}$ has attracted only modest attention. ${ }^{3-7}$ In view of the fact that $\mathrm{Pb}$ will readily adopt several different valence states, unlike the alkaline earths, a comparison between the different $\mathrm{La}_{0.65} \mathrm{~A}_{0.35} \mathrm{MnO}_{3}(\mathrm{~A}=\mathrm{Ca}, \mathrm{Sr}, \mathrm{Ba}, \mathrm{Pb})$ doping systems is important. ${ }^{6,7}$ Furthermore, it is possible that different dopants will affect the surface enthalpy differently ${ }^{8,9}$ and, consequently, the surface electronic structure and/or surface composition.

The termination layer of the perovskite manganese oxides, $\mathrm{La}_{1-x} \mathrm{~A}_{x} \mathrm{MnO}_{3}(\mathrm{~A}=\mathrm{Ca}, \mathrm{Sr}, \mathrm{Ba} ; x=0.1,0.35)$ has been studied using angle resolved $\mathrm{x}$-ray photoemission spectroscopy,${ }^{8-10}$ ion scattering spectroscopy, ${ }^{11,12}$ and angleresolved photoemission. ${ }^{13-15}$ The termination layer of $\mathrm{La}_{1-x} \mathrm{~A}_{x} \mathrm{MnO}_{3}$, with $x=0.35$, has been consistently determined to be at least partly $\mathrm{Mn}-\mathrm{O} .^{8-15}$ Unfortunately, because the surface free energy is expected to be different with the bulk, surface segregation is expected and has been routinely observed in some manganese perovskite oxides. $^{8-10,16,17}$ This paper explores whether $\mathrm{La}_{0.65} \mathrm{~Pb}_{0.35} \mathrm{MnO}_{3}$ exhibits a similar surface composition to $\mathrm{La}_{0.65} \mathrm{~A}_{0.35} \mathrm{MnO}_{3}(\mathrm{~A}=\mathrm{Ca}, \mathrm{Sr}, \mathrm{Ba})$ thus has a similar surface free enthalpy.

\section{SAMPLE PREPARATION AND EXPERIMENTAL DETAILS}

The crystalline samples with a nominal thickness of $1000 \AA$ A were grown on (100) $\mathrm{LaAlO}_{3}$ substrates by rf sputtering in a 4:1 argon/oxygen atmosphere at 15 mTorr with the substrate maintained at a temperature of $300 \mathrm{~K}$. The films

a) Author to whom correspondence should be addressed; electronic mail: pdowben@unl.edu were annealed at $650{ }^{\circ} \mathrm{C}$ for $10 \mathrm{~h}$ and $850{ }^{\circ} \mathrm{C}$ for $2 \mathrm{~h}$ in an oxygen atmosphere maintained at a pressure of 1 atm (this is less annealing than used for the alkaline doped earth manganese perovskites because of lead evaporation). The bulk chemical composition of the films was determined from energy dispersive analysis of $\mathrm{x}$-ray emission spectroscopy (XES or EDAX) and found to be similar to the targets with the final compositions $\mathrm{La}_{0.65} \mathrm{~Pb}_{0.35} \mathrm{MnO}_{3}$. SQUID measurements of the sample magnetization variation with temperature indicate a Curie temperature of $350 \mathrm{~K}$. The crystallinity and orientation was established by $\mathrm{x}$-ray diffraction. The samples were further characterized by temperature dependence magnetoresistance. The peak temperature of resistivity versus temperature curve shifted to $420 \mathrm{~K}$ at a $5.5 \mathrm{~T}$ magnetic field, and a negative relative magnetoresistance of $47 \%$ was observed at $320 \mathrm{~K}$ in this field. Figure 1 shows both the zero field and high field $(5.5 \mathrm{~T})$ resitivities (left-hand side

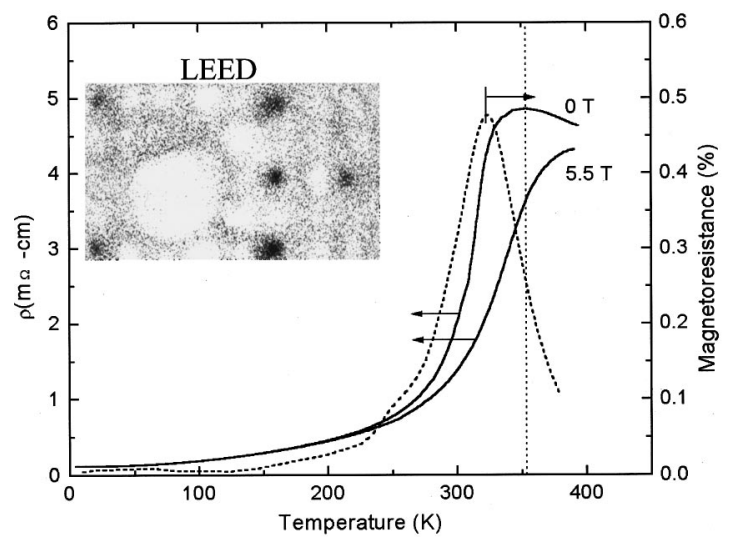

FIG. 1. The measured magnetoresistance (right-hand side axis) and resistivity as a function of temperature at zero field and high field (5.5 T) (left-hand side axis), for the $1 \mu \mathrm{m}$ thick film. The inset shows the fourfold symmetry of the electron diffraction spots, obtained by LEED. 


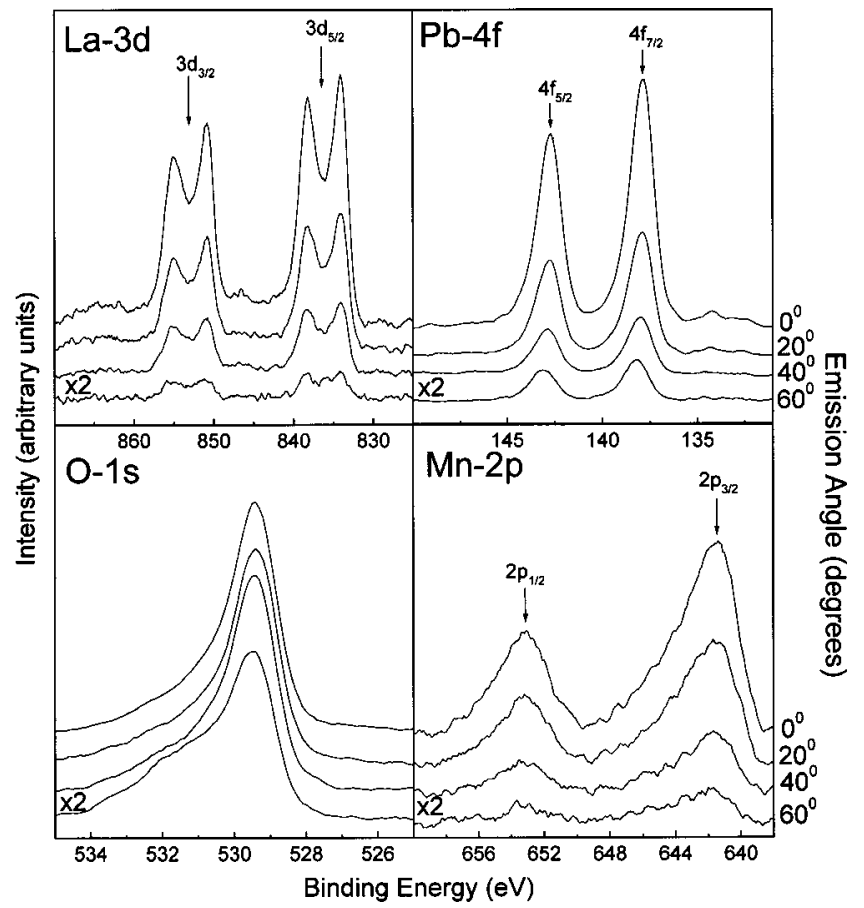

FIG. 2. The X-ray photoemission spectra of the $\mathrm{La} 3 d, \mathrm{~Pb} 4 f, \mathrm{O} 1 s$, and Mn $2 p$ core levels of $\mathrm{La}_{0.65} \mathrm{~Pb}_{0.35} \mathrm{MnO}_{3}$. The spectra were taken as a function of emission angle of the photoelectron and plotted as a function of binding energy.

axis) as well as the variation of magnetoresistance (MR) as a function of temperature (right-hand side axis).

$\mathrm{X}$-ray photoemission spectroscopy was undertaken with the $\mathrm{Mg} K \alpha$ line (1253.6 eV) from a PHI Model 04-548 Dual Anode x-ray source. Energy distribution curves of the elemental core levels were acquired with a large hemispherical electron energy analyzer (PHI Model 10-360 Precision Energy Analyzer). The Fermi level was established from tantalum in electrical contact with the sample. The binding energy of core levels is reported with respect to this Fermi level and the emission angle with respect to the surface normal. Sample surfaces were cleaned in ultrahigh vacuum by repeated annealing and exposure to low energy electrons to stimulate the desorption of contaminants as described elsewhere. ${ }^{14}$

\section{EXPERIMENTAL RESULTS AND DISCUSSIONS}

Core level photoemission data are shown for $\mathrm{La}_{0.65} \mathrm{~Pb}_{0.35} \mathrm{MnO}_{3}$ in Fig. 2. Both the core level binding energies and peak shapes are similar to that reported previously for $\mathrm{La}_{1-x} \mathrm{Ca}_{x} \mathrm{MnO}_{2.97}$ (by Choi et al. ${ }^{18}$ and Taguchi and Shimada ${ }^{19}$ ) and for $\mathrm{La}_{1-x} \mathrm{Sr}_{x} \mathrm{MnO}_{3}$ (Choi et al. ${ }^{18}$ and Saitoh et $a l^{20}{ }^{20}$. The core level data generally suggest that the $\mathrm{O}-\mathrm{Mn}-\mathrm{O}$ layers in $\mathrm{La}_{0.65} \mathrm{~Pb}_{0.35} \mathrm{MnO}_{3}$ have fewer defects than is the case for $\mathrm{La}_{0.65} \mathrm{~A}_{0.35} \mathrm{MnO}_{3}(\mathrm{~A}=\mathrm{Ca}, \mathrm{Sr})$ consistent with the better low energy electron diffraction (LEED) pattern obtained from $\mathrm{La}_{0.65} \mathrm{~Pb}_{0.35} \mathrm{MnO}_{3}$ than is the case for $\mathrm{La}_{0.65} \mathrm{~A}_{0.35} \mathrm{MnO}_{3} \quad(\mathrm{~A}=\mathrm{Ca}, \mathrm{Sr}) .{ }^{9}, 10,14,21$ The LEED pattern is shown as an inset in Fig. 1 and it shows the approximate fourfold symmetry of the film's surface.
The oxygen core level can provide indications of the presence of defects in the manganese perovskites. ${ }^{18}$ As shown in Fig. 2, the oxygen $1 s$ core level of the perovskite manganese oxide $\mathrm{La}_{0.65} \mathrm{~Pb}_{0.35} \mathrm{MnO}_{3}$, exhibits one dominant peak at a binding energy of $529.4 \mathrm{eV}$ and a shoulder at higher binding energies. This is very similar to other manganese perovskites. ${ }^{18}$ The higher binding energy $\mathrm{O} 1 s$ peak found at $531.3 \mathrm{eV}$, in the perovskites, has been attributed to either a different surface oxide or to oxygen associated with defects in the perovskite structure though exact nature of the oxygen species giving rise to this $531.3 \mathrm{eV}$ feature has not yet been determined. ${ }^{18}$ Compared to the other manganese perovskites, in $\mathrm{La}_{0.65} \mathrm{~Pb}_{0.35} \mathrm{MnO}_{3}$, this satellite feature is quite weak.

The Mn $2 p$ spectra from the $\mathrm{La}_{0.65} \mathrm{~Pb}_{0.35} \mathrm{MnO}_{3}$ sample indicates that the disorder in the surface region is not as significant as in many other manganese perovskites. ${ }^{18}$ The full width at half maximum (FWHM) of the Mn $2 p$ core level spectra is about $4 \mathrm{eV}$ as compared to $4-4.5 \mathrm{eV}$ for $\mathrm{La}_{0.65} \mathrm{Ca}_{0.35} \mathrm{MnO}_{3}$ and $\mathrm{La}_{0.65} \mathrm{Sr}_{0.35} \mathrm{MnO}_{3} .{ }^{18}$ The relatively narrow $\mathrm{Mn} 2 p$ half width is consistent with the restriction of $\mathrm{Mn}$ to a single valence state and an absence of significant numbers of defects in the surface region. The Mn $3 p_{3 / 2}$ core level binding energies (shown in Fig. 2) of $641.5 \mathrm{eV}$ for $\mathrm{La}_{0.65} \mathrm{~Pb}_{0.35} \mathrm{MnO}_{3}$ is very similar to that observed for $\mathrm{Mn}_{3} \mathrm{O}_{4}$ $(641.6 \mathrm{eV})^{18}$ and smaller than observed for $\mathrm{La}_{0.65} \mathrm{Sr}_{0.35} \mathrm{MnO}_{3}$ $\left(\begin{array}{llll}642.5 & \mathrm{eV}\end{array}\right),{ }^{18,20} \quad \mathrm{La}_{0.65} \mathrm{Ca}_{0.35} \mathrm{MnO}_{3} \quad(641.8 \mathrm{eV}),{ }^{18,19}$ $\mathrm{LaMn}^{3+} \mathrm{O}_{3}(642.0 \mathrm{eV})^{22,23}$ and $\mathrm{Mn}^{4+} \mathrm{O}_{2}(642.4 \mathrm{eV})^{22,23}$ but slightly greater than that observed for $\mathrm{Mn}_{2} \mathrm{O}_{3}(641.1 \mathrm{eV})$, and $\mathrm{MnO}(640.6 \mathrm{eV}) .{ }^{18}$ As with the arguments put forward by Choi et al. ${ }^{18}$ and Taguchi and Shimada, ${ }^{19}$ we propose that the $\mathrm{Mn} 2 p$ binding energies for $\mathrm{La}_{0.65} \mathrm{~Pb}_{0.35} \mathrm{MnO}_{3}$ are consistent with $\mathrm{a} \mathrm{Mn}^{3+}$ state rather than a $\mathrm{Mn}^{4+}$ state in the surface region. This assignment is consistent with the fact there is substantial $\mathrm{Pb}$ segregation (as discussed later) since $\mathrm{Pb}$ is allowed higher oxidation states than the generally expected alkaline earth $\mathrm{A}^{2+}$ state $(\mathrm{A}=\mathrm{Ca}, \mathrm{Sr})$ and this would act to lower the corresponding oxidation state of nearby $\mathrm{Mn}$ from $4+$ to $3+$.

The binding energy of the $\mathrm{Pb} 4 f_{7 / 2}$ core level increases from 137.8 to $138.2 \mathrm{eV}$ with increasing emission angle as seen in Figs. 2 and 3(b). These binding energies are greater than observed for the $\mathrm{Pb}^{2+}$ state seen in PbTe $[137.3 \mathrm{eV}$ (Ref. 24)], PbS [137.5 eV (Ref. 24)], and PbO [137.4 (Ref. 25)]. Since the greater the emission angle, the more surface sensitive the $\mathrm{x}$-ray photoemission signal, the higher binding energies for the $\mathrm{Pb} 4 f_{7 / 2}$ at greater emission angles indicates an effectively higher oxidation of $\mathrm{Pb}$ in the surface region consistent with a concomitant lower oxidation of $\mathrm{Mn}$ in the surface region. Thus the mixed $\mathrm{Mn}^{4+/ 3+}$ state of the $\mathrm{La}_{0.65} \mathrm{~A}_{0.35} \mathrm{MnO}_{3}(\mathrm{~A}=\mathrm{Ca}, \mathrm{Sr})$ materials is suppressed in favor of a $\mathrm{Mn}^{3+}$ state in the case of the surface region of $\mathrm{La}_{0.65} \mathrm{~Pb}_{0.35} \mathrm{MnO}_{3}$ as indicated by the core level binding energies of $\mathrm{Pb}, \mathrm{Mn}$, and by the $\mathrm{Mn}$ core level half width.

The XPS core level data can also be utilized to observe the surface segregation in the manganese perovskites, ${ }^{8-10}$ because the effective mean free path of the escaping electrons becomes shorter with increasing emission angle. The data in Fig. 3 show the measured intensity ratio of the $\mathrm{Pb}$ to La core 


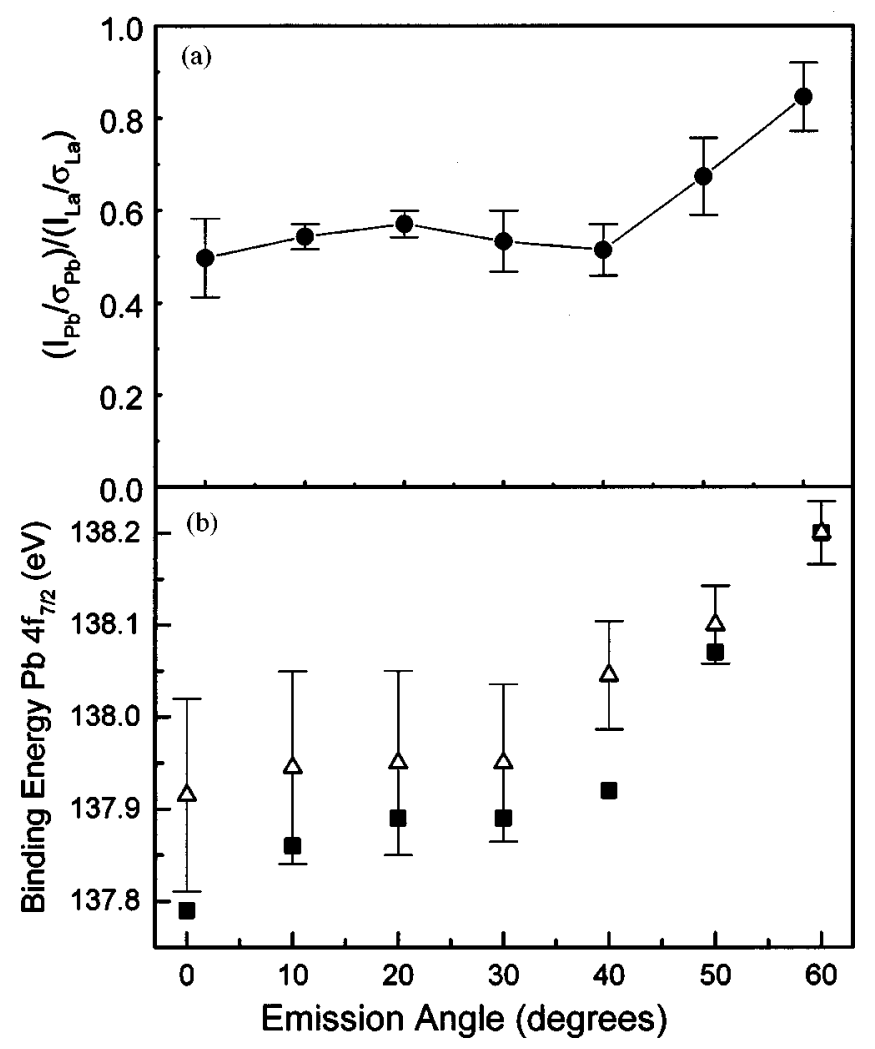

FIG. 3. (a) The emission angle dependence of the x-ray photoemission data. The $\mathrm{Pb} 4 f_{7 / 2}$ intensity relative to the La $3 d_{5 / 2}$ intensity as a function of emission angle normalized by cross section; (b) the $\mathrm{Pb} 4 f_{7 / 2}$ binding energy is plotted as a function of emission angle at $300 \mathrm{~K}(\triangle)$ and $200 \mathrm{~K}$ (

level, which increases as a function of the increasing emission angle. Qualitatively this shows that the surface region is $\mathrm{Pb}$ rich. In Fig. 3(a) of are several data points taken at different temperatures averaged together. The error bars are quite small and we conclude that the surface segregation profile does not change significantly with temperature between 200 and $300 \mathrm{~K}$.

\section{SUMMARY}

Surface segregation in the complex oxides is relatively common and has now been identified in another manganese perovskite. The influence of the surface segregation and surface defects does appear to have some affect upon the core level binding energies and the data suggest that while $\mathrm{La}_{0.65} \mathrm{~Pb}_{0.35} \mathrm{MnO}_{3}$ is $\mathrm{MnO}_{2}$ terminated, the $\mathrm{Mn}$ is in the $3+$ state due to corresponding higher oxidation states of $\mathrm{Pb}$ in the $\mathrm{Pb}$ rich subsurface layer.

\section{ACKNOWLEDGMENTS}

This work was supported by NSF through Grant No. DMR-98-02126 and the Joint Center for Atom Technologies (JRCAT) through the Atomic Technology Partnership and the Center for Materials Research and Analysis (CMRA) at the University of Nebraska. The authors thank Hani Dulli for his critical comments.

${ }^{1}$ M. Imada, A. Fujimori, and Y. Tokura, Rev. Mod. Phys. 70, 1039 (1998).

${ }^{2}$ A. P. Ramirez, J. Phys.: Condens. Matter 9, 8171 (1997).

${ }^{3}$ Y. X. Jia et al., Phys. Rev. B 52, 9147 (1995).

${ }^{4}$ R. Mahendiran et al., J. Phys. D 28, 1743 (1995).

${ }^{5}$ J. Q. Wang et al., Appl. Phys. Lett. 71, 3418 (1997).

${ }^{6}$ R.-M. Thomas, V. Skumryev, J. M. D. Coey, and S. Wirth, J. Appl. Phys. 85, 5384 (1999).

${ }^{7}$ M. T. Causa et al., Phys. Rev. B 58, 3233 (1998).

${ }^{8}$ J. Choi, C. Waldfried, S.-H. Liou, and P. A. Dowben, J. Vac. Sci. Technol. A 16, 2950 (1998).

${ }^{9}$ J. Choi, J. Zhang, S.-H. Liou, P. A. Dowben, and E. W. Plummer, Phys. Rev. B 59, 13453 (1999).

${ }^{10}$ H. Dulli, P. A. Dowben, J. Choi, S.-H. Liou, and E. W. Plummer (unpublished).

${ }^{11}$ M. Yoshimoto, H. Maruta, T. Ohnishi, K. Sasaki, and H. Koinuma, Appl. Phys. Lett. 73, 187 (1998).

${ }^{12}$ M. Izumi et al., Appl. Phys. Lett. 73, 2497 (1998).

${ }^{13}$ J. Zhang et al., Solid State Commun. 97, 39 (1996).

${ }^{14}$ D. N. Mcllroy et al., Phys. Rev. B 54, 17438 (1996).

${ }^{15}$ A. A. Zakharov et al., Phys. Rev. B 56, 9030 (1997).

${ }^{16}$ W. Zhang, X. Wang, and I. Boyd, Appl. Phys. Lett. 73, 2745 (1998).

${ }^{17}$ L.-C. Dufour, G. L. Bertrand, G. Caboche, P. Decorse, A. El Anssari, A. Poirson, and M. Vareille, Solid State Ionics 101-103, 661 (1997).

${ }^{18}$ J. Choi et al., Phys. Status Solidi B 214, 45 (1999).

${ }^{19}$ H. Taguchi and M. Shimada, J. Solid State Chem. 67, 37 (1987).

${ }^{20}$ T. Saitoh et al., Phys. Rev. B 51, 13942 (1995).

${ }^{21}$ J.-H. Park, E. Vescovo, H. J. Kim, C. Kwon, R. Ramesh, and T. Venkatesan, Nature (London) 392, 794 (1998).

${ }^{22}$ D. J. Lam, B. W. Veal, and D. E. Ellis, Phys. Rev. B 22, 5730 (1980).

${ }^{23}$ S. P. Kowalczyk et al., Phys. Rev. B 11, 1721 (1975).

${ }^{24}$ R. B. Shalvoy et al., Phys. Rev. B 15, 1680 (1977); L. R. Pederson et al., J. Spectrosc. Rel. Phenom. 28, 203 (1982).

${ }^{25}$ K. S. Kim, J. O’Leary, and N. Winograd, Anal. Chem. 45, 2214 (1973). 